\title{
Stable Cellulose Separator Based on Sodium Chloride for Lithium-Ion Battery
}

\section{Do Chun Nam Kung}

Sangmyung University - Seoul Campus

Sang Wook Kang ( $\nabla$ swkang@smu.ac.kr)

Sangmyung University https://orcid.org/0000-0001-7211-4064

\section{Research Article}

Keywords: Stable cellulose, sodium chloride, lithium-ion battery, pro-environmental process, manufacturing, morphology, thermostability

Posted Date: January 19th, 2022

DOI: https://doi.org/10.21203/rs.3.rs-1166178/v1

License: (c) (1) This work is licensed under a Creative Commons Attribution 4.0 International License. Read Full License 


\section{Abstract}

In this study, we fabricated porous membrane based on cellulose acetate by adding $\mathrm{NaCl}$ for a low cost and pro-environmental process. We succeeded in manufacturing the cellulose acetate (CA)/ $\mathrm{NaCl}$ composites with small micro-sized pores for stable separator. $\mathrm{NaCl}$ existed as ionic aggregates in $\mathrm{CA}$ polymer and disrupts the interaction between $\mathrm{CA}$ chains. Thus, the $\mathrm{CA} / \mathrm{NaCl}$ composites were plasticized. Plasticized regions of the $\mathrm{CA} / \mathrm{NaCl}$ composites became small micro-sized pore, applying hydrostatic force at 8 bar. The pore morphology of surface and cross section of the $\mathrm{CA} / \mathrm{NaCl}$ composites were confirmed by SEM. The small micro-sized pores were measured by water flux. In addition, the interaction between $\mathrm{NaCl}$ and functional group of CA was measured by using FT-IR spectroscopy. TGA was used to identify for thermostability of the $\mathrm{CA} / \mathrm{NaCl}$ composites matrix.

\section{Introduction}

Porous materials have been important in various fields.(Cheng et al. 2020, Costa et al. 2019, Kumar et al. 2019, Slater and Cooper 2015, Sun et al. 2016, Gunathilake et al. 2017, Zhai and Jana 2017) Among porous materials, porous membranes are used in chemical products and various fields. The porous membrane is used to purify wastewater or to remove contaminants floating in the air as a filter in biology, environmental engineering, etc. (Cheng et al. 2020, Gunathilake et al. 2017, Zhai and Jana 2017) It is also applied as a separator to separate the positive and negative electrodes of batteries in the electrochemistry. (Arora and Zhang 2004, Cannarella et al. 2014, Costa et al. 2019, Lagadec et al. 2016, Zhang 2007) In the battery, the separator separates the cathode and the anode to prevent an internal short circuit and serves as a passage for lithium ions to move between the cathode and the anode.(Arora and Zhang 2004, Costa et al. 2019, Zhang 2007) Separator must withstand the harsh environment thermally and electrochemically inside the battery. Thus, it must be thermally, chemically and electrochemically stable to both the electrode and electrolyte, and it must have good mechanical strength. (Cannarella et al. 2014, Lagadec et al. 2016) The materials mainly used for battery separator are polyolefin materials such as polypropylene and polyethylene. It is economically advantageous because it is inexpensive and has good mechanical properties.(Choi et al. 2001, Heidari and Mahdavi 2020, Lagadec et al. 2018) Thus, it is widely used as a battery separator. However, polypropylene separator has a low thermal decomposition temperature. Therefore, there is a problem of stability such as battery explosion when the battery become overheated. To increase the stability of the polypropylene separator, a method of coating ceramic particles on the polypropylene separator was used.(Choi et al. 2010, Liu et al. 2014, Shi et al. 2014) Liu et al., coated the $\mathrm{Al}_{2} \mathrm{O}_{3} / \mathrm{SiO}_{2}$ composite ceramic layer on both sides of the polypropylene separator to not only strengthen the thermostability and mechanical strength of the polypropylene film, but also improve the electrolyte absorption and ionic conductivity of the separator surface.(Liu et al. 2014) However, the ceramic coating method is expensive and there are still problems for stability, such as a battery fire, since polypropylene is decomposed at a low temperature. Therefore, a battery separator was created based on cellulose acetate (CA), which has a higher thermal decomposition temperature than polypropylene (Asghar et al. 2020, Bhute and Kondawar 2019, Chen et al. 2018) and 
high stability was achieved by using electrospinning technique to manufacture a thermally and mechanically stable battery separator.(Boriboon et al. 2018, Chen et al. 2020, Yvonne et al. 2014, Zhang et al. 2013) In addition, there was a study to develop the process as an environmentally and low-cost process by using an additive in a cellulose acetate-based separator.(Hong et al. 2020, Kim and Kang 2021, Lee et al. 2021, Lee and Kang 2019, 2020) Lee et al., prepared a film by adding $\mathrm{CaCl}_{2}$ to a CA solution made using acetone and $\mathrm{H}_{2} \mathrm{O}$ at a mol ratio of 1:0.4, and applied water pressure to 8 bar to prepare a straight porous separator.(Lee et al. 2021) Kim et al., added lactic acid to the CA matrix with hydrostatic force to develop a separator with better thermal stability than separator consisting of polypropylene and polyethylene.(Kim and Kang 2021) Since high water pressure at 8 bar is applied to the film, a straight, porous separator can be easily fabricated. $\mathrm{H}_{2} \mathrm{O}$ and Acetone, which are used as solvents for dissolving CA, are cheap and widely used industrially. They can be easily separated and recycled. Therefore, it was possible to develop an eco-friendly and low-cost battery separator process.

In previous studies, Lee et al., demonstrated that an advanced porous separator can be fabricated by adding an inorganic compound such as a metal salt to a CA polymer solution.(Lee and Kang 2019, 2020) $\mathrm{Mg}\left(\mathrm{NO}_{3}\right)_{2} \cdot 6 \mathrm{H}_{2} \mathrm{O}$ was added to cellulose acetate to control the pore size on the surface of the CA matrix. (Lee and Kang 2019) In addition, using $\mathrm{Zn}\left(\mathrm{NO}_{3}\right)_{2} \cdot 6 \mathrm{H}_{2} \mathrm{O}$, the $\mathrm{Zn}\left(\mathrm{NO}_{3}\right)_{2} \cdot 6 \mathrm{H}_{2} \mathrm{O} / \mathrm{CA}$ separator was thermally stable and showed a water flux of $182 \mathrm{~L} / \mathrm{m}^{2} \mathrm{~h}$ at a water pressure at 8 bar.(Lee and Kang 2020) Hong et al., fabricated a thermally stable CA film with nano-pores by adding glycerin, an organic molecule, to cellulose acetate polymer without using a metal salts.(Hong et al. 2020) However, the method has the disadvantage that the additives used to make the film are expensive, even if the results are meaningful. In this study, $\mathrm{NaCl}$, the cheapest among salts, was applied to a low cost and pro-environmental process based on cellulose acetate. The suggested method has the advantage of being environmentally and low cost by using $\mathrm{CA}$ and $\mathrm{H}_{2} \mathrm{O}$. NaCl is cheaper than organic materials and metal salts used as additives. In addition, $\mathrm{NaCl}$ is the most common salts and the cheapest among inorganic salts. Therefore, $\mathrm{NaCl}$ was added to the process to fabricate a CA-based separator for practical applications.

\section{Experimental}

Sodium chloride and cellulose acetate $(C A, M n=\sim 50,000)$ were purchased from Sigma Aldrich Chemical CO. Acetone (Daejung Chemical \& Metals) was used as the solvent. All materials were used without pretreatment.

A $10 \mathrm{wt} \%$ neat CA solution was prepared by dissolving cellulose acetate polymer in a mixed solvent of acetone/water (wt/wt 8:2 ratio). $\mathrm{NaCl}$ was added to the $10 \mathrm{wt} \%$ neat CA solution as the mole ratio of 1:0.04. The solution was then stirred for $24 \mathrm{hr}$. After that, the film was fabricated by a free-standing method using a doctor blade on the glass plate. It was dried in a thermo-hygrostat at $25^{\circ} \mathrm{C}$ and $50 \%$ humidity for $30 \mathrm{~min}$. The dried film was placed in water pressure treatment equipment. And then, the mol ratio 1:0.04 $\mathrm{CA} / \mathrm{NaCl}$ matrix was applied by water-pressure from 2 to 8 bar. At this time, each time the 
pressure was increased by 1 bar, it was stabilized for 30 minute and the flux was measured. The unit of Flux is $L / m^{2} h(L M H)$. After that, the membranes were dried for $24 \mathrm{hr}$.

The surface and cross section of the $\mathrm{CA} / \mathrm{NaCl}$ membrane was observed using a SEM (JSM-5600LV, $\mathrm{JEOL}$ ). The interaction force between the functional group of cellulose acetate polymer and $\mathrm{NaCl}$ was analyzed by FT-IR spectroscopy (VERTEX 70/70V FT-IR spectrometers, Bruker Optics). The thermal stability of the CA polymer membrane was measured using TGA (Universal V4. 5A, TA instruments)

\section{Result \& Discussion}

SEM

SEM was used to determine the size and shape of pores on the surface of the CA membrane and the morphology of cross-section. Figure 1. is the surface of neat CA film. As shown in Figure 1.a) and b), the surface of neat CA film has almost no pores and is pristine. Figure 2. a), b) and c) show the surface of 1:0.04 $\mathrm{CA} / \mathrm{NaCl}$ membrane before applying water pressure. As shown in Figure 2. a), a few of pores were formed on the surface of 1:0.04 $\mathrm{CA} / \mathrm{NaCl}$ at 0 bar. In constant, Figure 2. c) has more pores on the surface than Figure 2. a). Figure 2. b) shows that the pores were formed with a larger size than Figure 2. a) and c). The reason that the size and number of pores are different on the surface of 1:0.04 CA/ $\mathrm{NaCl}$ at 0 bar is that $\mathrm{H}_{2} \mathrm{O}$ solvates $\mathrm{NaCl}$ as the form of ionic aggregates. $\mathrm{NaCl}$ in the state of ionic aggregates is relatively larger. Therefore, As shown in Scheme 1. $\mathrm{B}, \mathrm{NaCl}$ permeates between the cellulose acetate chains, increasing the distance between the chains. When the $\mathrm{CA} / \mathrm{NaCl}$ membrane is dried, $\mathrm{H}_{2} \mathrm{O}$ is evaporated. As water evaporates, the regions occupied by $\mathrm{H}_{2} \mathrm{O}$ forms the pores. At this time, depending on the dispersion of $\mathrm{NaCl}$, the size and the number of ionic aggregates of $\mathrm{NaCl}$ change and the number and size of pores are varied. Figure 3. a) and b) show the surface of 1:0.04 CA/ NaCl membrane treated with water pressure at 8 bar. As shown in Figure 3. a), many pores were formed and there were dents on the surface of 1:0.04 CA/NaCl at 8 bar. Figure $3 . b$ ) is an enlarged view of the surface of the membrane. In Figure 3. b), pores existed as smaller than $10 \mu \mathrm{m}$ were formed. This indicates that $\mathrm{NaCl}$ was dispersed in the CA matrix and small sized pores were formed due to the bottleneck phenomena when high waterpressure was applied. Figure 4. a) is a cross-section of a 1:0.04 CA/NaCl membrane at 0 bar. In the crosssection, the region with pores is the part where $\mathrm{H}_{2} \mathrm{O}$ is solvating $\mathrm{NaCl} . \mathrm{H}_{2} \mathrm{O}$ was evaporated as the membrane was dried, forming the pores on the cross section. Figure 4. b) shows a cross section of a 1:0.04 CA/ $\mathrm{NaCl}$ at 8 bar. As shown in Figure 4. b), the cross-section has a sponge form. As the distance between the cellulose polymer chains increased as $\mathrm{NaCl}$ was added, the $\mathrm{CA} / \mathrm{NaCl}$ composite was plasticized. When high hydraulic pressure is applied to this polymer, the plasticized part of the CA matrix is pierced by the hydraulic pressure, creating the pores and creating a nearly linear channel.

TGA

TGA was used to compare the thermal stability of neat $\mathrm{CA}, 1: 0.04 \mathrm{CA} / \mathrm{NaCl}$ at 0 bar, and $1: 0.04 \mathrm{CA} / \mathrm{NaCl}$ at 8 bar. Figure 5. a) shows the thermal decomposition temperature of neat $\mathrm{CA}, 1: 0.04 \mathrm{CA} / \mathrm{NaCl}$ at 0 bar, 
and 1:0.04 CA/ NaCl at 8 bar. Figure 5. b) is an enlarged graph of Figure 5. a). In Figure 5. b), 1:0.04 $\mathrm{CA} / \mathrm{NaCl}$ composite at 0 bar had the lowest thermal decomposition temperature among the three composites. Neat CA film was decomposed at about $300{ }^{\circ} \mathrm{C}$. however, the pyrolysis temperature of 1:0.04 $\mathrm{CA} / \mathrm{NaCl}$ at 0 bar is $249^{\circ} \mathrm{C}$. This indicates that the thermal stability of $1: 0.04 \mathrm{CA} / \mathrm{NaCl}$ at 0 bar decreases as the flexibility of $\mathrm{CA}$ membrane increases. $\mathrm{NaCl}$ added to $\mathrm{CA}$ was present as ionic aggregates, preventing the interaction between CA chains and increasing the flexibility. As a result, the CA matrix was plasticized and the pyrolysis temperature was lowered. On the other hand, the 1:0.04 CA/ NaCl composite at 8 bar was decomposed at about $264^{\circ} \mathrm{C}$, which is higher than the thermal decomposition temperature of $1: 0.04 \mathrm{CA} / \mathrm{NaCl}$ at 0 bar. This means that the thermostability of $1: 0.04 \mathrm{CA} / \mathrm{NaCl}$ at 8 bar increased since $\mathrm{NaCl}$ added to the $\mathrm{CA} / \mathrm{NaCl}$ composite was removed partially by water treatment, as shown in scheme $1 \mathrm{C}$. When $\mathrm{NaCl}$ was partially removed by water pressure, the interaction between CA polymer chains is recovered. Thus, pyrolysis temperature of 1:0.04 CA/ NaCl at 8 bar was recovered.

\section{Infrared spectroscopy}

FT-IR spectroscopy was used to identify the interaction force between the functional group of the cellulose polymers and $\mathrm{NaCl}$. Figure 6 . is an analysis of the functional group of $\mathrm{CA}$. Figure 6 . a) is ether peaks of neat CA, CA/NaCl at 0 bar and CA/ NaCl at 8 bar. The peak of three membranes was $1033 \mathrm{~cm}^{-1}$ for ether of CA polymer. According to Table 1. and Figure 7, there was no remarkable peak change in the deconvolution of ether peaks. Therefore, it was thought that ether of CA was not interacting with $\mathrm{NaCl}$.

Figure 6. b) is carbonyl group in IR spectrum of neat $\mathrm{CA}, \mathrm{CA} / \mathrm{NaCl}$ at 0 bar, $\mathrm{CA} / \mathrm{NaCl}$ at 8 bar. The peak of all membranes was $1737 \mathrm{~cm}^{-1}$ by the carbonyl group. However, the slight shift was observed for FT-IR spectra. Therefore, the shift was analyzed by deconvolution. (Figure 8) According to Table 2, in neat CA, the area in the range of $1728 \mathrm{~cm}^{-1}$ occupied $14.27 \%$. For the area in the range of $1729 \mathrm{~cm}^{-1}, 44.67 \%$ was observed and the area at $1749 \mathrm{~cm}^{-1}$ occupied $41.06 \%$. When $\mathrm{NaCl}$ was added to neat CA polymer, the area decreased to $6.39 \%$ in the range of $1728 \mathrm{~cm}^{-1}$, and the ratio of the area in the range of $1729 \mathrm{~cm}^{-1}$ increased to $50.05 \%$. In other words, when $\mathrm{NaCl}$ was added to neat CA polymer, the proportion of areas with relatively high wavenumbers increased. This indicates the vibration of the $\mathrm{C}=\mathrm{O}$ bond is strengthened by $\mathrm{NaCl}$. Looking at Scheme $1 \mathrm{~A}$, neat CA polymer chains exists close to each other. Therefore, the intermolecular interaction between the carbonyl groups of the chain became strengthened. However, when $\mathrm{NaCl}$ is added to $\mathrm{CA}$ polymer, $\mathrm{NaCl}$ is solvated as ionic aggregates and penetrated into CA chains. Thus, as in Scheme $1 \mathrm{~B}$, the intermolecular interaction between carbonyl groups is weakened by the increasing distance between cellulose polymer chains. As a result, the $\mathrm{C}=\mathrm{O}$ bond becomes stronger and vibrated at a high wavenumber.

Figure 6. c) is the hydroxyl group for IR data of neat $\mathrm{CA}, \mathrm{CA} / \mathrm{NaCl}$ at 0 bar, $\mathrm{CA} / \mathrm{NaCl}$ at 8 bar. The peak at $3490 \mathrm{~cm}^{-1}$ was observed for neat CA, and at $3483 \mathrm{~cm}^{-1}$ for the $\mathrm{NaCl}$-added CA composites. This is the peak shifted by adding $\mathrm{NaCl}$ to the $\mathrm{CA}$ polymer. Therefore, the shift was analyzed by deconvolution. (Figure 9) According to Table 3, when $\mathrm{NaCl}$ is added to neat $\mathrm{CA}$, the ratio of the area in the wavenumber of $3493 \mathrm{~cm}^{-1}$ increased by $4.5 \%$, and the ratio of the area in the wavenumber of $3616 \mathrm{~cm}^{-1}$ decreased by 
$4.5 \%$. However, when 1:0.04 $\mathrm{CA} / \mathrm{NaCl}$ membrane was applied by water pressure at 8 bar, the ratio of the area in the two ranges was not significantly changed. Even though the change in ratio of area was not exactly observed, this change means the hydroxyl group of CA polymer was interacting with $\mathrm{NaCl} . \mathrm{NaCl}$ is interacting with the hydroxyl group of CA polymer while the distance between the cellulose acetate chains became lengthened like Scheme $1 \mathrm{~B}$. The interaction of hydroxyl group with $\mathrm{NaCl}$ would have been observed at a relatively low wavenumber. However, when $\mathrm{CA} / \mathrm{NaCl}$ membrane was applied by water pressure at 8 bar, $\mathrm{NaCl}$ is partially removed. Thus, the intermolecular interaction between the hydroxyl group and $\mathrm{NaCl}$ become recovered to a higher wavenumber. However, since the amount of $\mathrm{NaCl}$ to be removed was imperceptible, no significant change was observed in the IR data.

Table 1. deconvolution of ether group IR date

\begin{tabular}{cccc}
\hline Wave number & Neat CA & CA / NaCl Obar & CA / NaCl 8bar \\
\hline $985.6 \mathrm{~cm}^{-1}$ & $6.000 \%$ & $6.370 \%$ & $6.260 \%$ \\
\hline $1034 \mathrm{~cm}^{-1}$ & $80.01 \%$ & $81.15 \%$ & $79.94 \%$ \\
\hline $1069 \mathrm{~cm}^{-1}$ & $9.250 \%$ & $8.970 \%$ & $9.540 \%$ \\
\hline $1087 \mathrm{~cm}^{-1}$ & $4.740 \%$ & $5.510 \%$ & $4.26 \%$ \\
\hline
\end{tabular}

Table 2. deconvolution of carbonyl group IR date

\begin{tabular}{cccc}
\hline Wave number & Neat CA & CA / NaCl Obar & CA / NaCl 8bar \\
\hline $1728 \mathrm{~cm}^{-1}$ & $14.27 \%$ & $6.390 \%$ & $7.540 \%$ \\
\hline $1729 \mathrm{~cm}^{-1}$ & $44.67 \%$ & $50.05 \%$ & $48.74 \%$ \\
\hline $1749 \mathrm{~cm}^{-1}$ & $41.06 \%$ & $43.56 \%$ & $43.72 \%$ \\
\hline
\end{tabular}

Table 3. deconvolution of hydroxyl group IR date

\begin{tabular}{cccc}
\hline Wavenumber & Neat CA & CA / NaCl at 0 bar & CA / NaCl at 8 bar \\
\hline $3493 \mathrm{~cm}^{-1}$ & $89.12 \%$ & $93.62 \%$ & $95.74 \%$ \\
$3616 \mathrm{~cm}^{-1}$ & $10.88 \%$ & $6.380 \%$ & $4.260 \%$ \\
\hline
\end{tabular}

\section{Water Flux}

By adjusting the ratio of $\mathrm{NaCl}$, the pore size of the $\mathrm{CA} / \mathrm{NaCl}$ membrane was controlled. When the water flux was measured by applying a water pressure at 8 bar to the $\mathrm{CA} / \mathrm{NaCl}$ membrane, the flux didn't show a 
proportional relationship as the mol ratio of $\mathrm{NaCl}$ increased. This means that there is an optimal ratio in which $\mathrm{NaCl}$ can be well dispersed. According to Table 4, the composition of $\mathrm{NaCl}$ that produced the best flux is 0.02 ratio, and the average flux is $4.84 \mathrm{~L} / \mathrm{m}^{2} \mathrm{~h}$. However, $4.711 \mathrm{~L} / \mathrm{m}^{2} \mathrm{~h}$, a value similar to the average flux of 0.02 ratio of $\mathrm{NaCl}$, is measured at 0.04 ratio, and the reproducibility is also enhanced. This indicates that micro-sized plasticized parts were formed in the $\mathrm{CA}$ matrix by $\mathrm{NaCl}$ and as water pressure was applied to the $\mathrm{CA} / \mathrm{NaCl}$ membrane, small-sized pores were formed, resulting in relatively low flux.

Table 4. Flux data based on $\mathrm{NaCl}$ mol ratio

\begin{tabular}{ccccc}
\hline ratio Flux $\left(\mathrm{L} / \mathrm{m}^{2} \mathrm{~h}\right)$ Flux $\left(\mathrm{L} / \mathrm{m}^{2} \mathrm{~h}\right)$ Flux $\left(\mathrm{L} / \mathrm{m}^{2} \mathrm{~h}\right)$ Average Flux $\left(\mathrm{L} / \mathrm{m}^{2} \mathrm{~h}\right)$ \\
\hline $\mathbf{0 . 0 4 0}$ & 22.909 & 7.149 & 0.000 & 4.711 \\
& 3.781 & 4.578 & 5.230 & \\
\cline { 2 - 4 } & 4.310 & 2.998 & 4.930 & 4.840 \\
\hline 0.020 & 4.204 & 3.854 & 4.512 & \\
& 304.694 & 27.549 & 54.801 & \\
& 6.789 & 54.410 & 13.938 & \\
\hline
\end{tabular}

\section{Conclusion}

In this study, we used $\mathrm{NaCl}$ as an additive, which is the cheapest of the additives used for the low cost and pro-environmental process. When $\mathrm{NaCl}$ is added to cellulose acetate, it exists as ionic aggregates in $\mathrm{CA}$ polymer and increases the distance between CA polymer chains. Due to these phenomena, the CA matrix becomes flexible and plasticized. The pores formed on the surface and the sponge-shaped pores in the cross-section of the mol ratio 1:0.04 $\mathrm{CA} / \mathrm{NaCl}$ membrane were observed by using SEM.

Furthermore, it was confirmed by using FT-IR that $\mathrm{NaCl}$ interacts with the functional group of CA. Through FT-IR spectroscopy, it was confirmed that $\mathrm{NaCl}$ interferes with the intermolecular interaction between the carbonyl groups and interacts with the hydroxyl group of CA. Based on the TGA data, the thermal decomposition temperature of the mol ratio 1:0.04 CA/ NaCl membrane applied water pressure at 8 bar was higher than that of the $\mathrm{CA} / \mathrm{NaCl}$ membrane at 0 bar. Through these properties, it was found that when high water pressure was applied to the $\mathrm{CA} / \mathrm{NaCl}$ film, $\mathrm{NaCl}$ was removed partially, and the thermal decomposition temperature was recovered. On the other hand, the water flux of the mol ratio 1:0.04 $\mathrm{CA} / \mathrm{NaCl}$ composite was measured as $4.711 \mathrm{~L} / \mathrm{m}^{2} \mathrm{~h}$, and reproducible data were obtained. It means that $\mathrm{NaCl}$ at $0.04 \mathrm{~mol}$ ratio was relatively well dispersed compared to other compositions and formed small micro-sized pores. Finally, we demonstrated that porous polymers can be fabricated by applying $\mathrm{NaCl}$ for low cost and pro-environmental process.

\section{Declarations}


Acknowledgements

This work was supported by a 2020 Sangmyung University research fund.

\section{References}

1. Arora P, Zhang Z (2004) Battery separators. Chem Rev 104:4419-4462

2. Asghar MR, Anwar MT, Xia G, Zhang J (2020) Cellulose/Poly (vinylidene fluoride hexafluoropropylene) composite membrane with titania nanoparticles for lithium-ion batteries. Mater Chem Phys 252:123122

3. Bhute MV, Kondawar SB (2019) Electrospun poly (vinylidene fluoride)/cellulose acetate/AgTiO2 nanofibers polymer electrolyte membrane for lithium ion battery. Solid State lonics 333:38-44

4. Boriboon D, Vongsetskul T, Limthongkul P, Kobsiriphat W, Tammawat $P$ (2018) Cellulose ultrafine fibers embedded with titania particles as a high performance and eco-friendly separator for lithiumion batteries. Carbohydr Polym 189:145-151

5. Cannarella J, Liu X, Leng CZ, Sinko PD, Gor GY, Arnold CB (2014) Mechanical properties of a battery separator under compression and tension. J Electrochem Soc 161:F3117

6. Chen W, Zhang L, Liu C, Feng X, Zhang J, Guan L, Mi L, Cui S (2018) Electrospun flexible cellulose acetate-based separators for sodium-ion batteries with ultralong cycle stability and excellent wettability: the role of interface chemical groups. ACS applied materials \& interfaces 10:2388323890

7. Chen Y, Qiu L, Ma X, Dong L, Jin Z, Xia G, Du P, Xiong J (2020) Electrospun cellulose polymer nanofiber membrane with flame resistance properties for lithium-ion batteries. Carbohydr Polym 234:115907

8. Cheng H, Lijie L, Wang B, Feng X, Mao Z, Vancso GJ, Sui X (2020) Multifaceted applications of cellulosic porous materials in environment, energy, and health. Progress in polymer science 106:101253

9. Choi J, Kim SH, Kim D (2010) Enhancement of thermal stability and cycling performance in lithiumion cells through the use of ceramic-coated separators. J Power Sources 195:6192-6196

10. Choi S, Kang H, Ryu E, Lee K (2001) Electrochemical properties of polyolefin nonwoven fabric modified with carboxylic acid group for battery separator. Radiat Phys Chem 60:495-502

11. Costa CM, Lee Y, Kim J, Lee S, Lanceros-Méndez S (2019) Recent advances on separator membranes for lithium-ion battery applications: From porous membranes to solid electrolytes. Energy Storage Materials 22:346-375

12. Heidari AA, Mahdavi H (2020) Recent Development of Polyolefin-Based Microporous Separators for Li- Ion Batteries: A Review. The Chemical Record 20:570-595

13. Hong SH, Cho Y, Kang SW (2020) Highly porous and thermally stable cellulose acetate to utilize hydrated glycerin. Journal of Industrial and Engineering Chemistry 91:79-84 
14. Kim SH, Kang SW (2021) Preparation of highly stable cellulose separator by incorporation of lactic acid. Cellulose:1-9

15. Kumar KV, Gadipelli S, Wood B, Ramisetty KA, Stewart AA, Howard CA, Brett DJ, Rodriguez-Reinoso F (2019) Characterization of the adsorption site energies and heterogeneous surfaces of porous materials. Journal of materials chemistry A 7:10104-10137

16. Lagadec MF, Zahn R, Wood V (2018) Designing polyolefin separators to minimize the impact of local compressive stresses on lithium ion battery performance. J Electrochem Soc 165:A1829

17. Lagadec MF, Ebner M, Zahn R, Wood V (2016) Communication-technique for visualization and quantification of lithium-ion battery separator microstructure. J Electrochem Soc 163:A992

18. Lee HJ, Cho Y, Kang SW (2021) Development of low-cost process for pore generation in cellulose acetate by utilizing calcium salts. Journal of Industrial and Engineering Chemistry 94:419-424

19. Lee WG, Kang SW (2020) Eco-friendly process for facile pore control in thermally stable cellulose acetate utilizing zinc (II) nitrate for water-treatment. Journal of Industrial and Engineering Chemistry 81:88-92

20. Lee WG, Kang SW (2019) Control of pore in cellulose acetate containing Mg salt by water pressure treatment for applications to separators. Journal of Industrial and Engineering Chemistry 70:103-106

21. Liu H, Xu J, Guo B, He X (2014) Effect of Al2O3/SiO2 composite ceramic layers on performance of polypropylene separator for lithium-ion batteries. Ceram Int 40:14105-14110

22. Shi C, Zhang P, Chen L, Yang P, Zhao J (2014) Effect of a thin ceramic-coating layer on thermal and electrochemical properties of polyethylene separator for lithium-ion batteries. J Power Sources 270:547-553

23. Slater AG, Cooper Al (2015) Porous materials. Function-led design of new porous materials. Science (New York, NY) 348:aaa8075

24. Sun M, Huang S, Chen L, Li Y, Yang X, Yuan Z, Su B (2016) Applications of hierarchically structured porous materials from energy storage and conversion, catalysis, photocatalysis, adsorption, separation, and sensing to biomedicine. Chem Soc Rev 45:3479-3563

25. Udenni Gunathilake T, Ching YC, Ching KY, Chuah CH, Abdullah LC (2017) Biomedical and microbiological applications of bio-based porous materials: A review. Polymers 9:160

26. Yvonne T, Zhang C, Zhang C, Omollo E, Ncube S (2014) Properties of electrospun PVDF/PMMA/CA membrane as lithium based battery separator. Cellulose 21:2811-2818

27. Zhai C, Jana SC (2017) Tuning porous networks in polyimide aerogels for airborne nanoparticle filtration. ACS applied materials \& interfaces 9:30074-30082

28. Zhang J, Liu Z, Kong Q, Zhang C, Pang S, Yue L, Wang X, Yao J, Cui G (2013) Renewable and superior thermal-resistant cellulose-based composite nonwoven as lithium-ion battery separator. ACS applied materials \& interfaces 5:128-134

29. Zhang SS (2007) A review on the separators of liquid electrolyte Li-ion batteries. J Power Sources 164:351-364 


\section{Schemes}

Scheme 1 is available in the Supplemental Files section

\section{Figures}
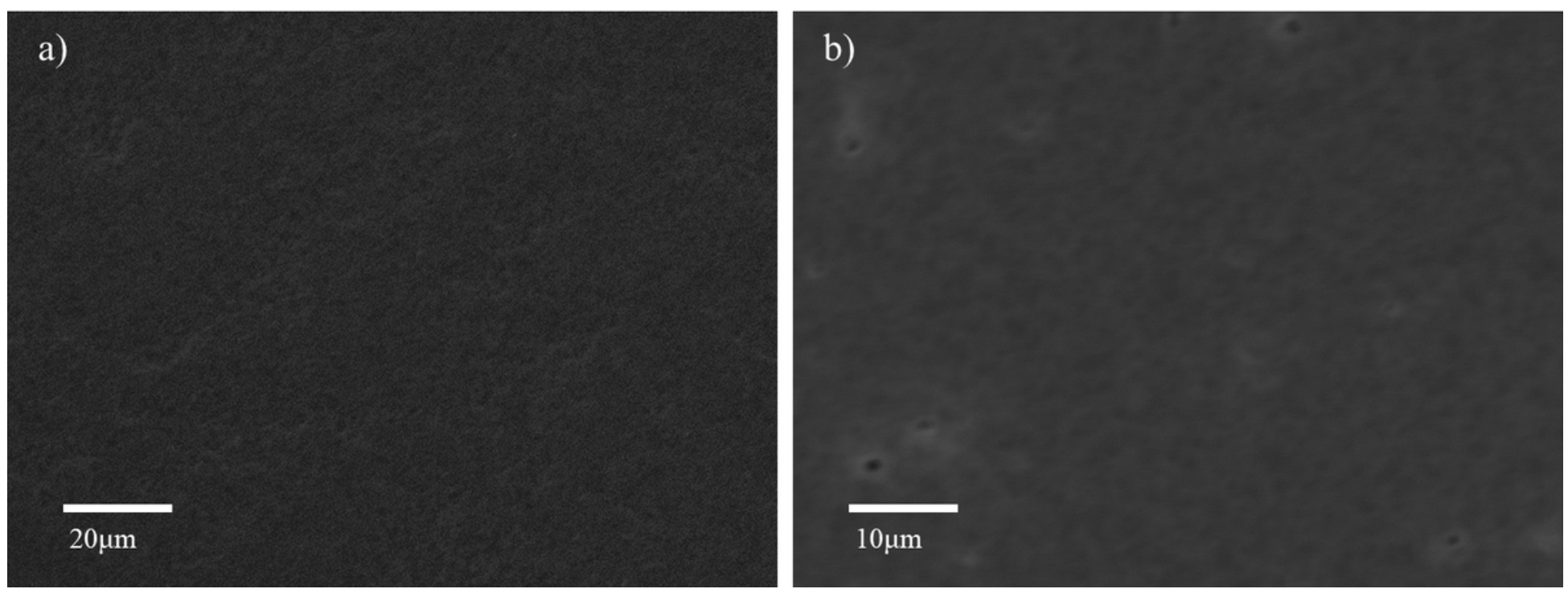

Figure 1

a) and b) surface of neat CA membrane surface without water pressure and $\mathrm{NaCl}$
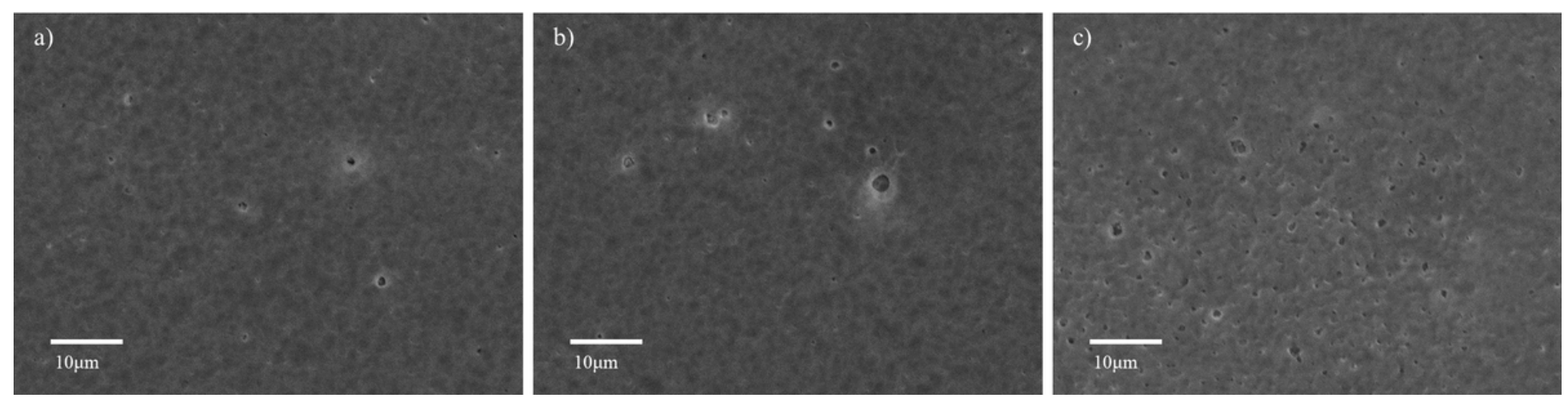

Figure 2

a), b) and c) surface of a mol ratio 1:0.04 $\mathrm{CA} / \mathrm{NaCl}$ membrane without water pressure 

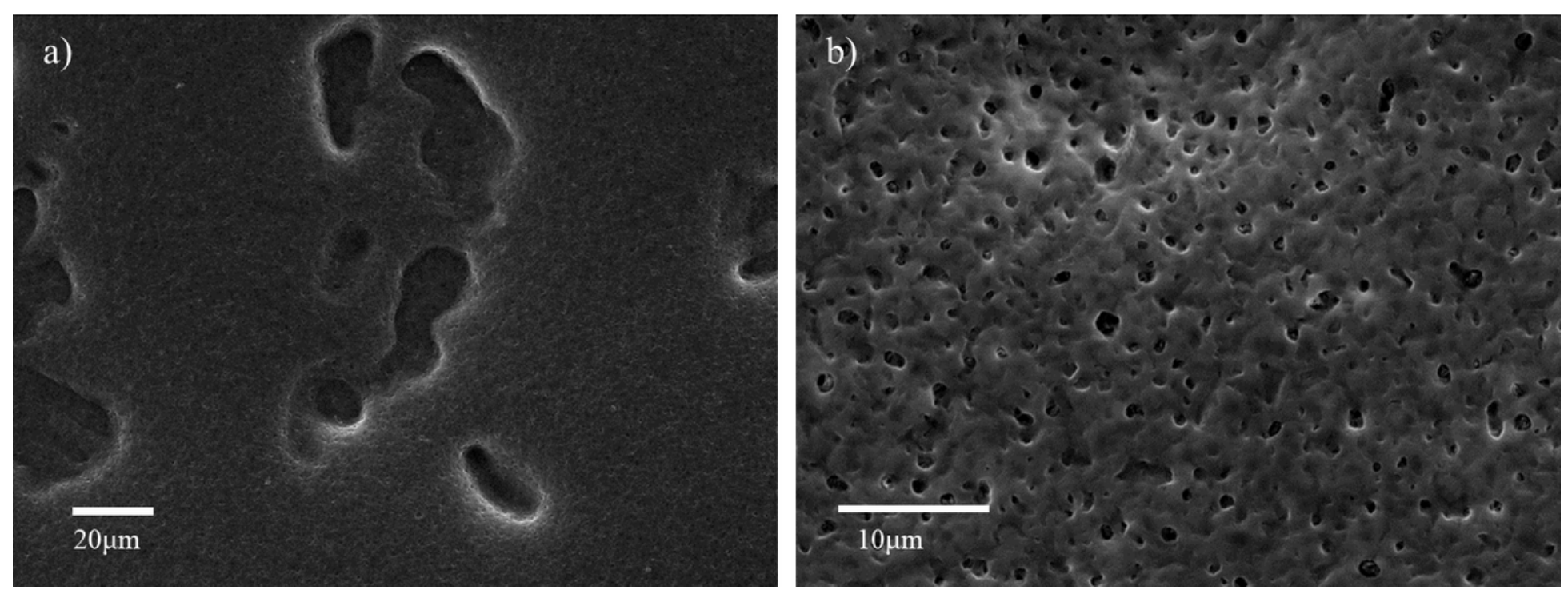

\section{Figure 3}

a) surface of a mol ratio 1:0.04 $\mathrm{CA} / \mathrm{NaCl}$ membrane with water pressure at $8 \mathrm{bar}, \mathrm{b}$ ) enlargement of surface of a mol ratio 1:0.04 CA/ $\mathrm{NaCl}$ membrane with water pressure at 8 bar
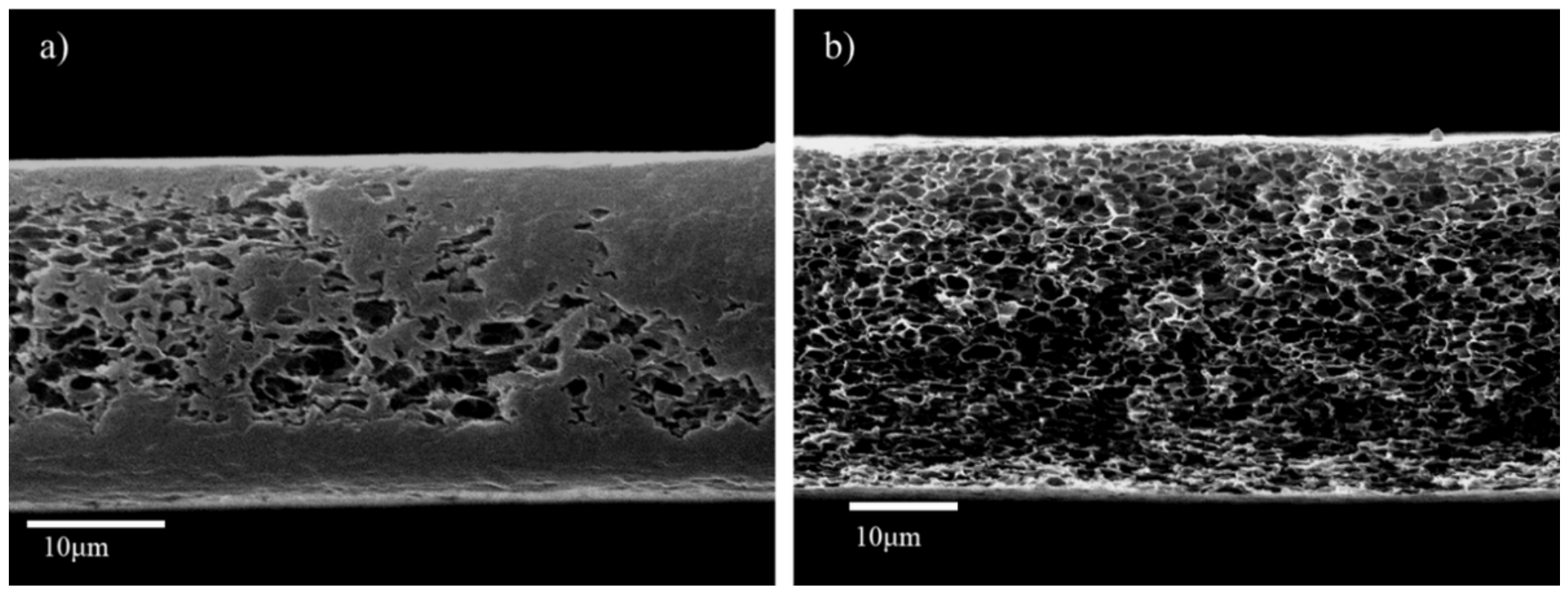

Figure 4

a) cross section of a mol ratio 1:0.04 $\mathrm{CA} / \mathrm{NaCl}$ membrane without water pressure, $b$ ) cross section of a mol ratio 1:0.04 $\mathrm{CA} / \mathrm{NaCl}$ membrane with water pressure at 8 bar 

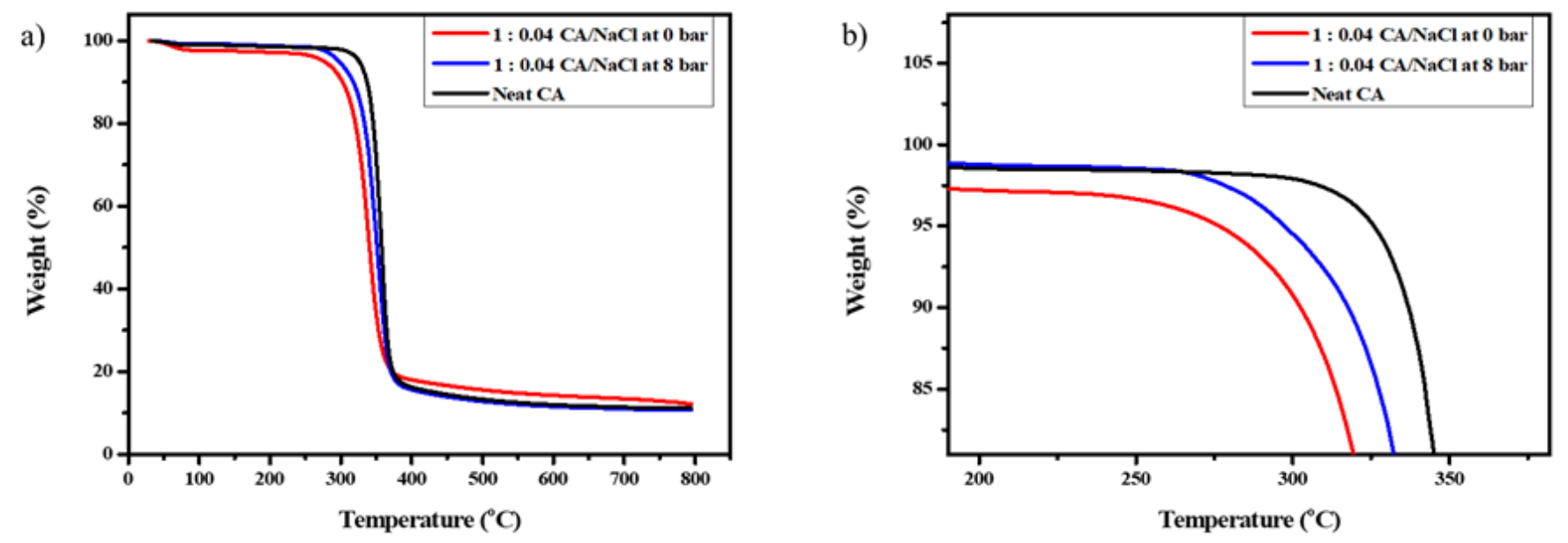

Figure 5

a) TGA data of Neat CA, 1:0.04 CA/NaCl membrane at 0 bar, 1:0.04 CA/NaCl membrane at 8bar, b) enlargement of a)
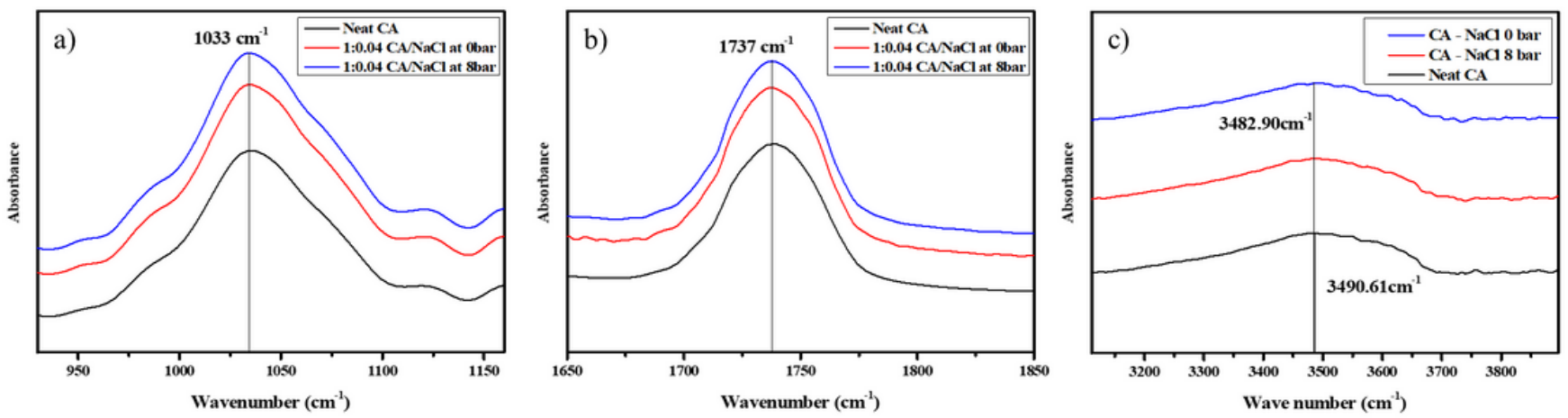

Figure 6

IR data of Neat CA, 1:0.04 CA/NaCl membrane at 0 bar, 1:0.04 CA/NaCl membrane at 8 bar
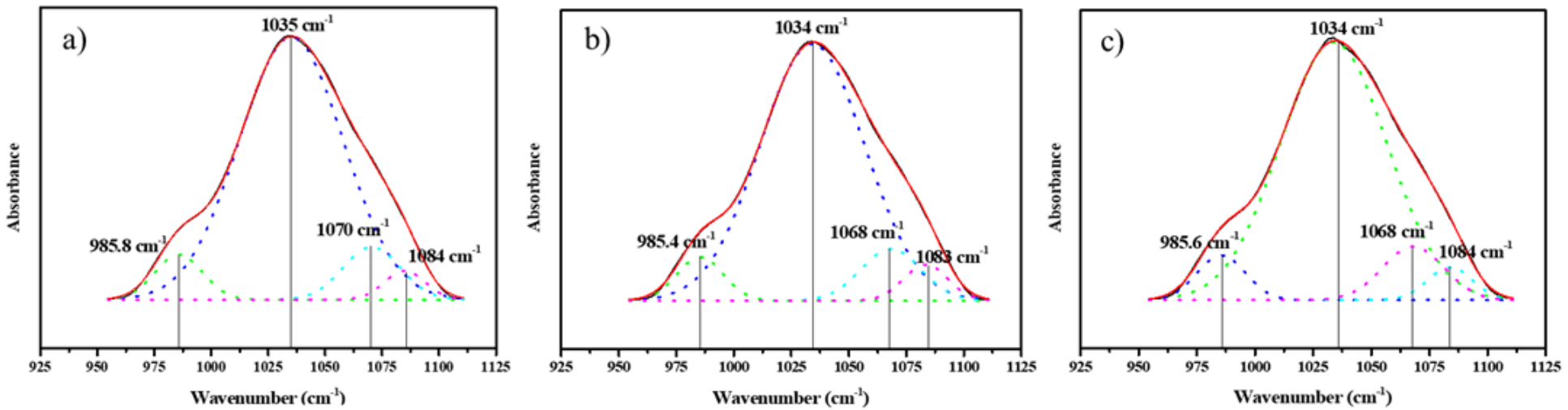
Figure 7

a) Ether group IR data deconvolution of Neat CA film, b) Ether group IR data deconvolution of 1:0.04 $\mathrm{CA} / \mathrm{NaCl}$ film at 0 bar, c) Ether group IR data deconvolution of 1:0.04 CA/ NaCl film at 8 bar
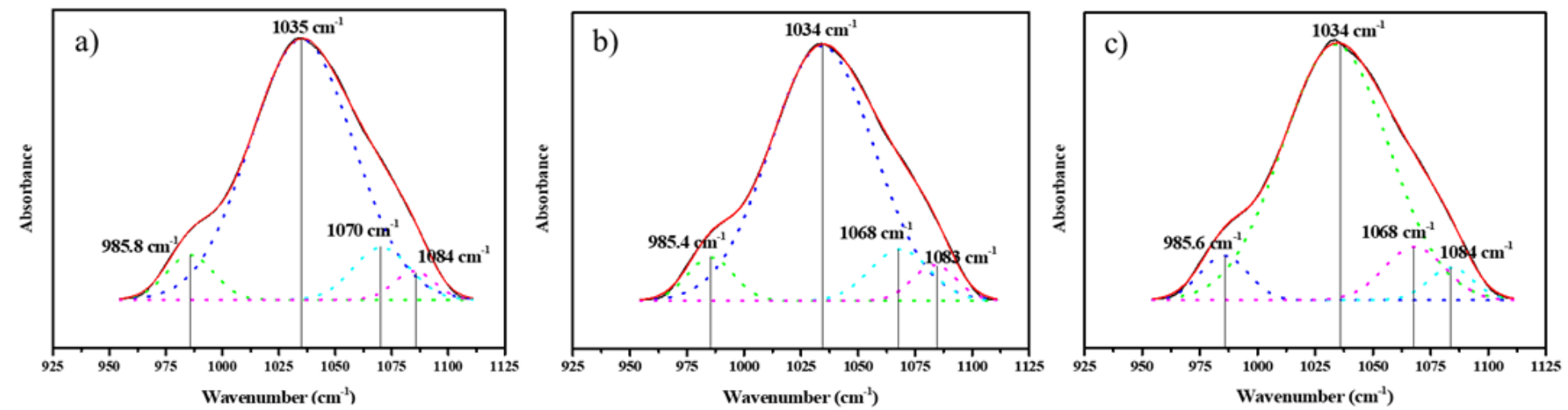

Figure 8

a) carbonyl group IR data deconvolution of Neat CA film, b) carbonyl group IR data deconvolution of 1:0.04 CA/ $\mathrm{NaCl}$ film at 0 bar, c) carbonyl group IR data deconvolution of 1:0.04 CA/ $\mathrm{NaCl}$ film at 8 bar
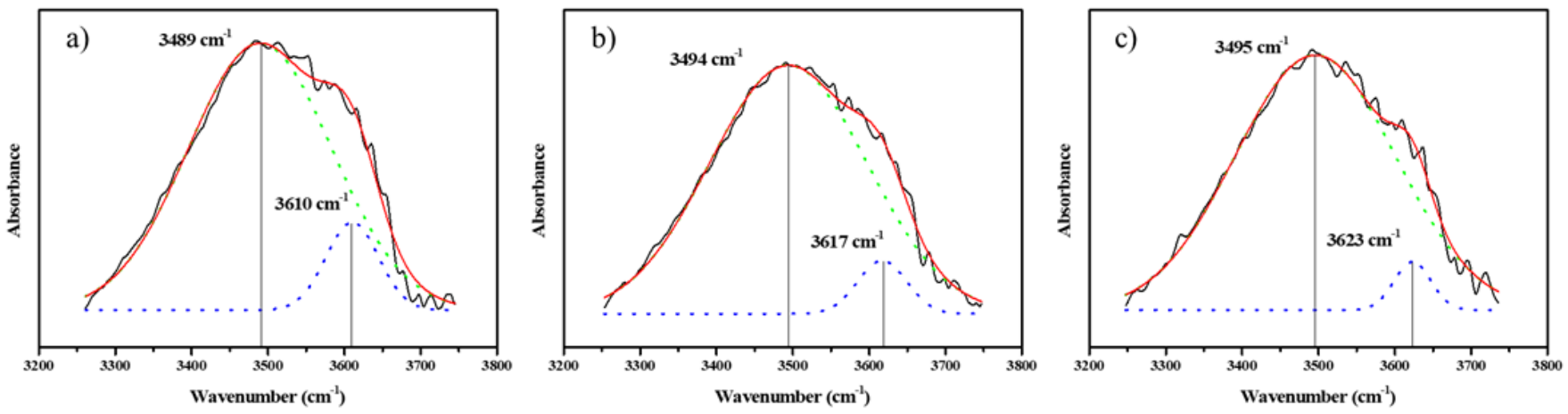

Figure 9

a) hydroxyl group IR data deconvolution of Neat CA film, b) hydroxyl group IR data deconvolution of 1:0.04 CA/ $\mathrm{NaCl}$ film at 0 bar, c) hydroxyl group IR data deconvolution of 1:0.04 CA/ NaCl film at 8 bar

\section{Supplementary Files}

This is a list of supplementary files associated with this preprint. Click to download.

- Scheme1.png 